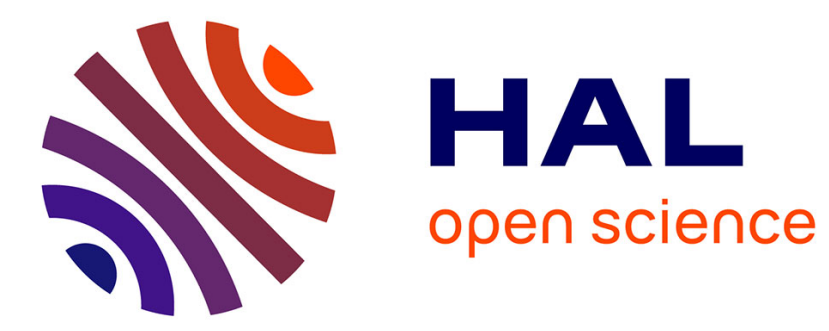

\title{
Dynamics of silver nanoparticles at the solution/biofilm/mineral interface
}

\author{
Morgane Desmau, Alexandre Gélabert, Clément Levard, Georges
}

Ona-Nguema, Vladimir Vidal, Joanne E Stubbs, Peter Eng, Marc F Benedetti

\section{- To cite this version:}

Morgane Desmau, Alexandre Gélabert, Clément Levard, Georges Ona-Nguema, Vladimir Vidal, et al.. Dynamics of silver nanoparticles at the solution/biofilm/mineral interface. Environmental science.Nano, 2018, 5 (10), pp.2394-2405. 10.1039/C8EN00331A . hal-02126673

\section{HAL Id: hal-02126673 \\ https://hal.science/hal-02126673}

Submitted on 12 May 2019

HAL is a multi-disciplinary open access archive for the deposit and dissemination of scientific research documents, whether they are published or not. The documents may come from teaching and research institutions in France or abroad, or from public or private research centers.
L'archive ouverte pluridisciplinaire HAL, est destinée au dépôt et à la diffusion de documents scientifiques de niveau recherche, publiés ou non, émanant des établissements d'enseignement et de recherche français ou étrangers, des laboratoires publics ou privés. 


\title{
Dynamics of silver nanoparticles at the solution/biofilm/mineral interface
}

\author{
Morgane Desmau ${ }^{a}$, Alexandre Gélabert ${ }^{a}$, Clément Levard ${ }^{\text {b, } c}$, Georges Ona-Nguema ${ }^{\mathrm{d}}$, Vladimir \\ Vidal $^{b}$, Joanne E. Stubbs ${ }^{e}$, Peter J. Eng ${ }^{e, f}$ and Marc F. Benedetti ${ }^{a}$
}

The extensive use of silver nanoparticles (AgNPs) is likely to result in their significant environmental release, and thus raises important concerns regarding their impact to ecosystems. In soils, bacterial biofilms can be found as mineral coatings, forming a complex interface that exhibits highly specific physico-chemical properties. As a result, this environmental compartment is likely to partly control the AgNPs fate. However, the interaction modes undergone by nanoparticles at this solution/biofilm/mineral are not yet well constrained. The dynamics of AgNPs interactions at a Shewanella oneidensis MR-1 biofilm - corundum $\left(\alpha-\mathrm{Al}_{2} \mathrm{O}_{3}\right)$ interface were investigated by Long Period - X-Ray Standing Waves - Fluorescence Yield Spectroscopy. Three different nanoparticle coatings of various properties $\left(\mathrm{PVP}, \mathrm{SiO}_{2}\right.$ and $\mathrm{SiO}_{2}-$ $\mathrm{NH}_{2}$ ) were tested, showing important differences in AgNPs partitioning and stability at this complex interface. The behavior of the two AgNPs coated by an organic layer, but of opposite charge $\left(\mathrm{SiO}_{2}\right.$ and $\left.\mathrm{SiO}_{2}-\mathrm{NH}_{2}\right)$, indicates that at firstorder, electrostatic interactions control the AgNPs partitioning at the solution/biofilm/mineral interface. In addition, the comparative study of the organic PVP-coated and the inorganic $\mathrm{SiO}_{2}$-coated AgNPs, both negatively charged, highlights the controls imposed by the nanoparticles size and hydrophobic properties on their interactions with this complex interface.

\section{Introduction}

In the past 15 years nanoparticles (NPs) have been increasingly produced and incorporated into various industrial products with an estimated production of 285,500 metric tons in $2010^{1}$. Silver nanoparticles (AgNPs) are among the 10 major engineered nanomaterials, with an average production volume of 275 tons in $2012^{2}$, and are incorporated in 383 products as of $2013^{3}$. They are mainly used for their anti-microbial properties, either in textiles, cosmetics or in building materials ${ }^{2}$. Most engineered AgNPs are composed of an $\mathrm{Ag}^{0}$ core surrounded by an (in)organic coating of varying composition and molecular weight ${ }^{4}$. These coatings aim at controlling AgNPs growth and shape during their synthesis, at stabilizing the AgNPs suspension in various solvents, and at providing specific surface properties to the particles ${ }^{4-7}$. The rapid increase in production of AgNPs, their wide use, and their toxicity have simultaneously raised societal concerns regarding their inevitable release into the natural environment as well as their potential adverse effects on human beings and ecosystems ${ }^{8-12}$. Predictive studies based on modeling approaches, and focusing on NPs environmental fluxes, indicate that soils, landfills and sediments should be considered as highly accumulating compartments ${ }^{1,3,13,14}$. Recently, Sun et al. (2016) ${ }^{14}$ developed a dynamic probabilistic model to estimate AgNPs fluxes to soil at 2.7 ton/year, with a total amount of stored AgNPs in soils calculated at

\footnotetext{
+ IPGP, Université Sorbonne Paris Cité, CNRS UMR 7154, Paris France

${ }^{b}$ CEREGE, Aix-Marseille Univ., CNRS, IRD, Technopôle de l'Arbois Méditerranée, BP80, 13545 Aix en Provence cedex 4, France

c. iCEINT, Int Consortium Environm Implicat Nanotechnol, France

d. IMPMC, Sorbonne Université, UMR 7590 CNRS, MNHN, IRD, Campus Pierre \& Marie Curie, 4 place Jussieu, Paris, France

e. Center for Advanced Radiation Sources, University of Chicago Chicago, IL, USA

f. James Franck Institute, University of Chicago, Chicago, IL, USA

† corresponding authors: desmau@ipgp.fr, gelabert@ipgp.fr

Electronic Supplementary Information (ESI) available: [details of any supplementary information available should be included here]. See DOI: $10.1039 / x 0 x x 00000 x$
}

15 tons as of 2014. However, even if such approaches consider an always increasing number of parameters, it remains challenging to access the real NPs environmental concentrations. To better assess the NPs environmental fluxes, it is thus of critical importance to specifically and accurately understand the AgNPs distribution and transformation in soils, identified as the main sink for NPs.

On the basis of our knowledge of colloid and metal(oid) cycling in natural systems, mineral surfaces and microbial biofilms are likely to strongly control NPs environmental transfer and fate in soils ${ }^{15-19}$. Biofilms are by far the main organization mode for bacteria ${ }^{20}$. They consist of an association of cells within an organic matrix of biological origin composed partly of EPS matrix (Extracellular Polymeric Substances), coating an organic or inorganic surface ${ }^{21}$. This EPS favors cell aggregation and adhesion, and the overall organization provides protection against biocides $20,22,23$. In addition, their gel-like structures favor the creation of microenvironments within the biofilms, allowing the existence of local specific redox conditions, $\mathrm{pH}$, or nutrient concentrations ${ }^{20}$. The transport of water, chemical elements, nutrients, metabolic residues, and complex chemical species within the biofilm thickness occurs via canals ${ }^{24}$. These canals are organized at three different levels. First, the bulk solution connects locally to the biofilm's deepest layer via the main channels (order of magnitude: $\mu \mathrm{m}$ ). They allow the transport of elements by advection and diffusion through the whole biofilm thickness. At the second level, smaller conduits are defined by the presence of EPS and are dominated by advective processes. Finally, at the smallest scale $(\mathrm{nm})$, cellular aggregates and higher EPS densities only allow ions and particle transport by diffusion ${ }^{20}$. Biofilm matrix density can vary depending on various parameters such as biofilm aging, microbial strains, nutrient medium, or type and surface of mineral substrate, and thus modify the transport of ions, molecules, or particles in these structures.

Biofilms are one of the most reactive compartments in soils owing to specific micro-environments within their thickness that can impact the fate of metals and NPs. Indeed, the role of EPS in AgNPs stabilization has been demonstrated for periphytic biofilms ${ }^{25}$ 
and for EPS extract from Pseudomonas putida ${ }^{26}$. This last study showed that EPS is able to enhance $\mathrm{Ag}$ and $\mathrm{CeO}_{2} \mathrm{NPs}$ stability by forming NPs-EPS complexes. Kroll et al. $(2014)^{25}$ also observed the formation of AgNPs when $\mathrm{Ag}^{+}$was present with EPS, and that these interactions can have important environmental impacts. However, only a limited number of studies have investigated in-situ, at the nano-scale (few $\mathrm{nm}$ ), AgNPs interaction with biofilms 10, 27, 28. Moreover, biofilms are known to coat mineral surfaces in soils, and both compartments of this interface are known to be highly reactive due to the high functional site densities of their surfaces ${ }^{15}$. Yet, the fate of AgNPs at this interface has not been investigated. It is thus important to understand and to quantify the interaction of AgNPs with the biofilm and the mineral surface for a better interpretation and understanding of the fate of AgNPs in soils. In addition, study conducted on the fate of AgNPs when they were in contact with organic matter, soil solution or directly in contact with agricultural soil ${ }^{29-31}$ highlights the role of AgNPs' surface charge on their interaction and the role of organic matter in stabilizing NPs. Molecular weight, hydrophobicity and coating composition have also been identified as parameters controlling NPs' stability in solution ${ }^{32,}{ }^{33}$. It is therefore important to consider these parameters when studying biofilm/NPs interactions to obtain a full understanding of the fate of AgNPs in soil. Thus, coating type effects on AgNPs stability and subsequent interactions with this interface also need to be investigated.

To address these questions, the current study monitors AgNPs transport at an interface composed of a well-defined mineral surface coated with a single-species bacterial biofilm of Shewanella oneidensis MR-1 and probes the impact of NPs size and coating type (surface charge, hydrophobicity, etc.) with three different AgNPs, representative of those used in commercial products. S. oneidensis MR-1 is a well-characterized bacterium commonly found in soils, sediments and aquifers. The interactions between AgNPs and the solution/biofilm/mineral interface are studied by Long Period - XRay Standing Waves - Fluorescence Yield (LP-XSW-FY) and Scanning Electron Microscopy (SEM). LP-XSW-FY spectroscopy allows measurement of in-situ element partitioning, at the nanometer scale, within the interface which is separated into biofilm and mineral surface compartments. LP-XSW-FY was previously successfully used to study $\mathrm{Zn}$ and $\mathrm{Pb}$ partitioning at a similar interface and to probe AgNPs surface oxidation in contact with organic matter and inorganic compounds ${ }^{16-19,34}$. Here we provide, for the first time, evidence that LP-XSW-FY method can be used to probe the fate of metallic manufactured NPs at the complex solution/biofilm/mineral interface. This method also enables quantification of NPs distribution between the biofilm and the mineral surface, highlighting the importance of chemical interactions (electrostatic, hydrophobic interactions) and NPscoating' nature in the fate of NPs at the solution/biofilm/mineral interface in soil.

\section{Material and Methods}

\subsection{AgNPs characterization}

In order to investigate the impacts of NPs surface charge and coating type, three different AgNPs were used. They were purchased from NanoComposix Europe. They all exhibit a 50 $\mathrm{nm}$ spherical $\mathrm{Ag}^{0}$ core, associated with three different coatings. The first one is polyvinylpyrrolidone (PVP), one of the most widely used organic coatings, and has a hydrodynamic diameter of $\sim 60 \mathrm{~nm}$ indicated a coating thickness of $5 \mathrm{~nm}^{26}$, 35 . The others have coating thicknesses of $20 \mathrm{~nm}$ of silica $\left(\mathrm{SiO}_{2}\right)$ or amino-silica $\left(\mathrm{SiO}_{2}-\mathrm{NH}_{2}\right)$, and thus have a total hydrodynamic diameter of $90 \mathrm{~nm}$. AgNPs size, zeta potential and hydrodynamic diameter were characterized by the manufacturer. PVP-AgNPs were initially stored in MilliQ water while $\mathrm{SiO}_{2}$ and $\mathrm{SiO}_{2}-\mathrm{NH}_{2}$-AgNPs were stored in isopropanol. $\mathrm{SiO}_{2}$ and PVP-coated AgNPs zeta potential in $5 \mathrm{mM} \mathrm{NaNO}$ were also measured using Dynamic Light Scattering (ZetaSize, Malvern), in our laboratory. At $10 \mathrm{mg} / \mathrm{L}^{-1}$, a zeta potential of 28.1 $( \pm 2.8) \mathrm{mV}$ was measured for PVP-coated AgNPs at $\mathrm{pH} 7$ (table S1), while $\mathrm{SiO}_{2}$-coated AgNPs, exhibited a zeta potential of $-32.4( \pm 1.5)$ (table S1) meaning that both of these AgNPs are negatively charged at $\mathrm{pH}=7$. Due to the protonation of amine functional groups on the surface of $\mathrm{SiO}_{2}-\mathrm{NH}_{2}$-coated AgNPs, these were positively charged at $\mathrm{pH} 7$ (table S1). All of them are well-dispersed in $5 \mathrm{mM} \mathrm{NaNO}$ aqueous solution. The initial concentrations of $\mathrm{Ag}$ in AgNPs stock solutions were checked using inductively coupled plasma atomic emission spectroscopy (ICP-AES; iCAP 6200 ThermoFisher).

\subsection{Shewanella oneidensis MR-1 biofilm/ $\alpha-\mathrm{Al}_{2} \mathrm{O}_{3}(1-102)$ systems}

The crystals used for this study were highly polished and oriented single $\alpha-\mathrm{Al}_{2} \mathrm{O}_{3}(1-102)$ crystal surfaces (Pi-Kem Ltd.). Surface roughness was around $3 \AA \AA$ (commercial data) allowing their use in LP-XSW-FY spectroscopy studies. S. oneidensis MR1 is a facultative Gram-negative, rod-shaped bacterium capable of utilising as electron acceptors oxygen under aerobic conditions and various metals as well as nitrate under anoxic conditions 36,37 . This bacterium is ubiquitous in aquatic environments and its genetics and physico-chemical properties are well-known ${ }^{38}$. S. oneidensis surface charge and site densities are available ${ }^{39}$, and the surface is mostly negatively charged above $\mathrm{pH}$ equal to 4 because of deprotonated carboxylic and phosphoric groups ${ }^{39}$.

To obtain biofilms on $\alpha-\mathrm{Al}_{2} \mathrm{O}_{3}(1-102)$ crystal surfaces, the growth protocol of Wang et al (2016) ${ }^{18}$ was adapted. Crystals were cleaned prior to the biofilm growth to remove all residual organic matter, metals and anions. Crystals were washed with acetone, placed in $1 \mathrm{mM} \mathrm{NaOH}$ for 20 minutes then soaked in $0.01 \mathrm{M} \mathrm{HNO}_{3}$ for 20 minutes. Each step was followed by multiple rinses with MilliQ water. The cleaned crystals were then glued inside a bottle using silicone gel and the system (bottle, crystal and associated Tygon tubing) was autoclaved for $20 \mathrm{~min}$ at $121^{\circ} \mathrm{C}$. Following this step, crystals were exposed to $S$. oneidensis MR-1 suspension. This suspension was obtained by growth of $S$. oneidensis MR-1 on trypticase soy agar (TSA, BioMérieux, 51044 ) plates at $30^{\circ} \mathrm{C}$. Frozen cells from a stock (frozen in $20 \%$ glycerol at $-80^{\circ} \mathrm{C}$ ) were revived under aerobic conditions on TSA. Two subcultures were necessary in order to remove any traces of glycerol within bacteria. Subsequently the colonies were used to prepare a suspension with a target optical density (OD) of 0.96 at $600 \mathrm{~nm}$ (the reference $O D_{600 \mathrm{~nm}}$ value for the reproducibility of our cultures) in tripticase soy broth (TSB, BioMérieux, 51019). Then, $17 \mathrm{~mL}$ of this suspension were inoculated into a $1000 \mathrm{~mL}$ batch reactor containing $710 \mathrm{~mL}$ of TSB to obtain an initial $O_{600 \mathrm{~nm}}$ value of 0.05 . The reactor was continuously agitated at 1000 
rpm at room temperature for 22 hours, and bacteria were harvested in their late exponential growth phase at an absorbance of 1.35. Finally, this bulk cell suspension was poured in the sterile bottle containing the crystals, and left to settle for 1 hour to allow bacterial attachment to the crystal surface. The sterile synthetic growth medium was flushed for 10 days at a constant flow-rate of $0.4 \mathrm{~mL} \cdot \mathrm{min}^{-1}$ under sterile conditions. The growth medium is composed of $1.27 \mathrm{mM}$ $\mathrm{K}_{2} \mathrm{HPO}_{4}, 0.73 \mathrm{mM} \mathrm{KH}_{2} \mathrm{PO}_{4}, 5 \mathrm{mM}$ NaHEPES, $2 \mathrm{mM} \mathrm{NaHCO}_{3}, 9$ $\mathrm{mM}\left(\mathrm{NH}_{4}\right)_{2} \mathrm{SO}_{4}, 150 \mathrm{mM} \mathrm{NaCl}$, and $0.64 \mathrm{mM} \mathrm{CaCl}_{2}{ }^{18}$, with a pH adjusted to 7 . The use of the growth medium allows us to

Figure 1: Schematic explanation of LP-XSW-FY data reduction and analysis. See also annex 1 and figure $\mathrm{S} 1$ for more information.

better constrain the composition of the solution in contact with bacteria than TSB (TSB are generally contaminated with metals). Moreover, it is a nutrient-depleted medium and thus favours biofilm growth compared to planktonic cells.

After 10 days, biofilm/crystal systems were removed from the bottles and put in $10 \mathrm{~mL}$ Falcon centrifuge tubes containing a more depleted nutrient medium $(200 \mu \mathrm{M} \mathrm{CaCl}, 150 \mu \mathrm{M}$ $\mathrm{MgSO}_{4}, 90 \mu \mathrm{M}\left(\mathrm{NH}_{4}\right)_{2} \mathrm{SO}_{4}, 150 \mu \mathrm{M} \mathrm{KNO}, 10 \mu \mathrm{M} \mathrm{NaHCO}{ }_{3}, 5 \mu \mathrm{M}$ $\left.\mathrm{KH}_{2} \mathrm{PO}_{4}\right)^{18}$ to remove excess ions from the previous medium. They were stored at $4^{\circ} \mathrm{C}$ for less than 1 week until $\mathrm{x}$-ray measurements were performed. Note that biofilm/crystal systems were not exposed to AgNPs during this growth and washing procedure.

\subsection{Preparation of AgNPs-exposed biofilm/crystal samples}

The biofilm/crystal interfaces were then exposed to AgNPs solutions containing $1 \mathrm{mg} . \mathrm{L}^{-1}$ of $\mathrm{Ag}$ suspended in $5 \mathrm{mM} \mathrm{NaNO}_{3}$ for 3 or 24 hours. The $\mathrm{NaNO}_{3}$ solution was used to minimize aggregation, compared to electrolyte with $\mathrm{Ca}^{2+}$. To maintain acceptable living conditions for $S$. oneidensis, solution $\mathrm{pH}$ was adjusted to 7 continuously over the course of the experiment using $0.1 \mathrm{M} \mathrm{HNO}_{3}$ and $0.1 \mathrm{M} \mathrm{NaOH}$.

For each experimental condition (AgNPs type or exposure time) a new biofilm/crystal system was gently immersed in $40 \mathrm{~mL}$ of fresh NPs suspension in a $50 \mathrm{~mL}$ plastic tube. The biofilm/crystal system was placed upside down, biofilm facing the bottom of the tube, in order to avoid NPs settling. All tubes were protected from light with aluminium foil to avoid $\mathrm{Ag}$ photo reduction ${ }^{4}$ and gently shaken, using an automatic shaker at $20 \mathrm{rpm}$, to prevent any biofilm degradation while ensuring suspension mixing.

After 3 or 24 hours of exposure time, the AgNPs-exposed biofilm/crystal samples were removed from the solution, and placed in a sealed sample holder for LP-XSW-FY measurements. Ag uptake was estimated after 24 hours of exposure by biofilm digestion in a $2 \% \mathrm{HNO}_{3}$ solution and subsequent Ag measurement by ICP-AES (iCAP 6200 ThermoFisher).

A Zeiss Ultra Device SEM-FEG equipped with field emission gun was used to perform SEM imaging. Samples were analysed at 5 and $15-\mathrm{keV}$ electron energy, to assess topography (SESi or InLens detector) and chemical contrast (ESB or NTS BSD detector) in the biofilms and to obtain semi-quantitative

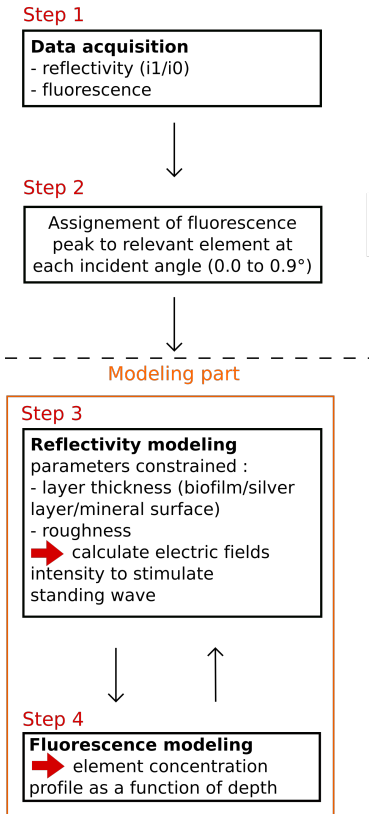

chemical composition
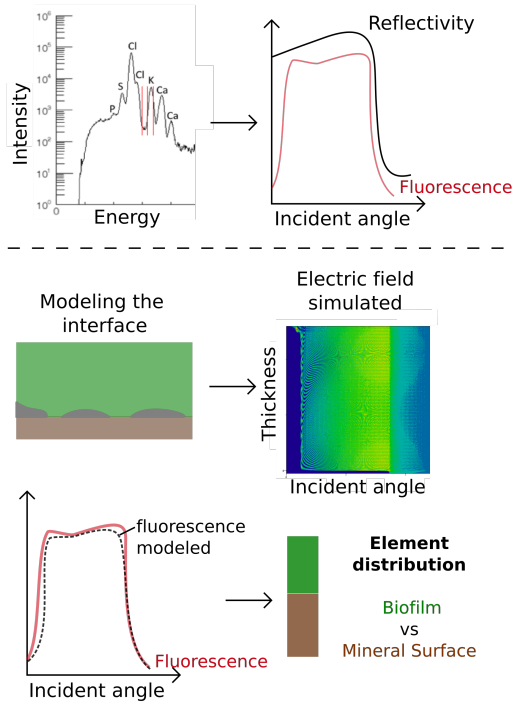

of NPs by Energy Dispersive Spectroscopy (EDS). The drying procedure for SEM analysis was as follows: each biofilm/crystal sample was successively immersed in aqueous mixtures of $50 \%$ ethanol for 5 minutes, $75 \%$ ethanol for 5 minutes, $90 \%$ ethanol for 5 minutes and finally $100 \%$ ethanol for 10 minutes in order to remove water prior to supercritical drying. Supercritical drying was performed on a Leica EM CPD300.

\subsection{LP-XSW-FY measurement and data analysis}

LP-XSW-FY is a synchrotron-based technique suitable for probing element partitioning at concentrations theoretically $>10 \mathrm{nM}^{18}$ in small-scale systems composed of biofilm coated mineral surfaces ${ }^{16,18,19}$. This technique allows us to observe and quantify partitioning between the biofilm and the mineral surface compartments. A full description of the technique is given in annex 1 and in the literature ${ }^{18,19,40}$. Each step of the data acquisition, treatment and modelling are presented in a simplified way in figure 1 and are detailed in annex 1 . Figure 2 presents a simplified schematic of the different possible results for a trace element distribution at the biofilm/mineral/interface.

Compared to other techniques used to study interactions between NPs and biofilms ${ }^{41,42}$, such as Scanning Transmission X-Ray Microscopy (STXM) or Confocal Laser Scanning Microscopy (CLSM), this technique allows us to study the whole system (biofilm+mineral) while STXM focuses on a specific part of the biofilm (ex: EPS-metal interactions). Moreover, no modification of the system is necessary to perform LP-XSW-FY measurement (e.g., drying, addition of fluorescent dyes, utilization of probe) whereas CLSM or TEM experiments cannot be performed without modifying the biofilm/mineral interface. 


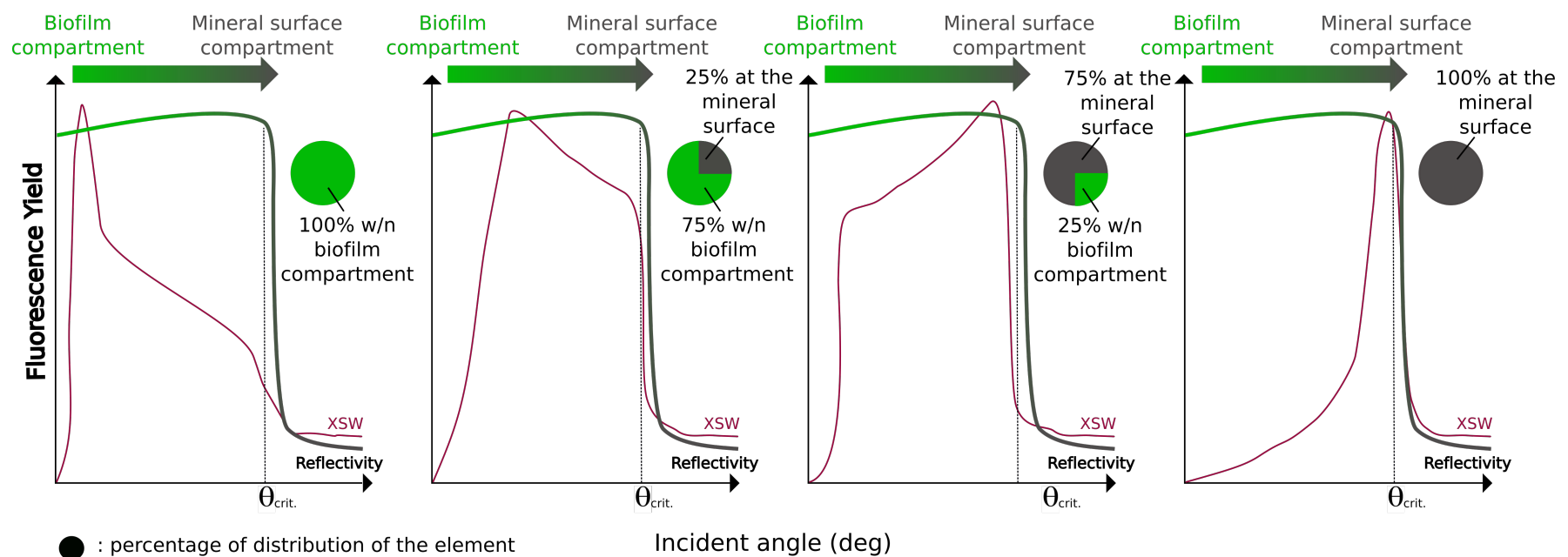
between the two compartments function of LP-XSW-FY profile

Figure 2: Schematic diagram showing LP-XSW-FY profiles that might be observed as a function of different elemental spatial distributions. This figure is adapted from Templeton et al., $2009^{40}$.

LP-XSW-FY measurements were conducted at beamline 13-ID$C$ at GeoSoilEnviroCARS (GSECARS) at the Advanced Photon Source (APS). The experimental set-up and beamline alignment are similar to the one described in Wang et al $(2016)^{18}$. Briefly $7 \mathrm{keV}$ and $14 \mathrm{keV} \mathrm{X}$-rays were selected using a cryo-cooled $\mathrm{Si}$ (111) monochromator and collimated using a pair of $1 \mathrm{~m}$-long Si mirrors in Kirkpatrick-Baez geometry. The beam profile of 10 x $1000 \mu \mathrm{m}$ (horizontal x vertical) was defined by slits. Fluorescence yield was measured using a 4-element silicon drift detector (SII NanoTechnology, Vortex-ME4) at incidence angles between $0.0^{\circ}$ and $0.9^{\circ}$. X-ray reflectivity was obtained by monitoring the incident $\left(I_{0}\right)$ and the reflected $\left(I_{1}\right)$ beam intensities using nitrogen-filled ion chambers. Biofilms were kept hydrated during the measurements by flowing humid helium through a Kapton-covered sample holder. Two to three locations were measured per sample to check for lateral spatial homogeneity of $\mathrm{Ag}$, with each location probing a surface area of $1 \mathrm{~mm} \times 1 \mathrm{~cm}$. We verified that a biofilm/crystal unexposed to AgNPs showed no Ag fluorescence allowing us to conclude that the measured $\mathrm{Ag}$ signal originates only from the AgNPs (Fig. S1).

\section{Results}

Initially, S. oneidensis biofilms are not uniformly distributed at the mineral surface. Large bacterial "islands" with variable thickness (Fig. S2.1.a) were found to be connected to each other by an organic matrix covering the mineral surfaces, consisting of the conditioning film (first layer on the substratum surfaces of absorbed organic molecules and EPS ${ }^{21}$ ), EPS and bacteria (Fig. S2.1.b). After 24 hours of exposure to AgNPs, the general biofilm structure appears to be less dense and some bacteria seem to be damaged (Fig. S2.1. c, d, e). The surfaces of the cells unexposed to Ag-NPs look smoother, while cells exposed to Ag-NPs look more misshapen and damaged.

The core/shell structure is visible for $\mathrm{Ag}-\mathrm{SiO}_{2}$ and $\mathrm{Ag}-\mathrm{SiO}_{2}-$ $\mathrm{NH}_{2}$ (Fig. S2.2. a, b). AgNPs composition was checked using EDS (Fig. S3a, b, c); $\mathrm{Ag}$ and $\mathrm{Si}$ are detected for $\mathrm{Ag}-\mathrm{SiO}_{2}$ and $\mathrm{Ag}-\mathrm{SiO}_{2-}$ $\mathrm{NH}_{2}$ whereas only $\mathrm{Ag}$ is detected when Ag-PVP NPs are analysed. $\mathrm{Ag}-\mathrm{SiO}_{2}$ and $\mathrm{Ag}-\mathrm{SiO}_{2}-\mathrm{NH}_{2} \mathrm{NPs}$ are aggregated (Fig.
S2.2. a, b) whereas Ag-PVP NPs are well dispersed (Fig. S2.2.c). Moreover, $\mathrm{Ag}-\mathrm{SiO}_{2}-\mathrm{NH}_{2} \mathrm{NPs}$ also associate with each other as chains (Fig. S2.2.b). Internalization of AgNPs was not observed, i.e. uptake of NPs inside bacterial cells, probably due to the size of AgNPs used. Indeed, if happening, internalization of AgNPs is more likely to happen for nanoparticles with a diameter smaller than $10 \mathrm{~nm}^{43}$.

Ag quantities in the biofilms at 24 hours were measured by ICPAES. Ag uptake within the solution/biofilm/mineral interface for Ag-PVP is $0.78 \pm 0.05 \mu \mathrm{g}$, corresponding to an uptake of 2.5 $\%$ of the initial $\mathrm{Ag}$ present in the supernatant, $0.30 \pm 0.05 \mu \mathrm{g}$ (4.2\%) for $\mathrm{Ag}-\mathrm{SiO}_{2}$ and $0.53 \pm 0.05 \mu \mathrm{g}$ (1.6\%) for $\mathrm{Ag}-\mathrm{SiO}_{2}-\mathrm{NH}_{2}$ from initial $\mathrm{Ag}$ masses in solution of $31.22 \pm 0.01 \mu \mathrm{g}, 7.17 \pm 0.01$ $\mu \mathrm{g}$ and $34.02 \pm 0.01 \mu \mathrm{g}$ respectively.

All locations measured for a given sample are similar. The critical angle is localized around $0.31 \pm 0.02^{\circ}$, see annex 1 (marked by the black vertical lines in Fig. 3 ). This value is in good agreement with the theoretical value of $\alpha-\mathrm{Al}_{2} \mathrm{O}_{3}(1-102)$ critical angle at $7 \mathrm{keV}: 0.32^{\circ}$. At 3 hours, Ag-PVP and $\mathrm{Ag}-\mathrm{SiO}_{2}-$ $\mathrm{NH}_{2}$ spectra have a $\mathrm{FY}$ peak well below the critical angle, at $0.17^{\circ}$ and $0.05^{\circ}$ at $7 \mathrm{keV}$, respectively. These peaks are followed by a decrease in the fluorescence until the critical angle is reached as marked by the black vertical lines (Fig. 3a, 3c). The decrease between the maximum peak intensity and the $\mathrm{FY}$ at the critical angle is greater for $\mathrm{Ag}-\mathrm{SiO}_{2}-\mathrm{NH}_{2}$ than for Ag-PVP NPs. The Ag-PVP FY profile is noisier than Ag-SiO ${ }_{2}-\mathrm{NH}_{2}$ because the Ag-PVP FY intensity is lower (Fig. 4a). The $\mathrm{Ag}-\mathrm{SiO}_{2}$ sample at 3 hours shows a different profile, with a FY peak at $0.31^{\circ}$ closed to the mineral critical angle with a low FY signal at smaller incident angles (Fig. 3b). The $\mathrm{Ag}-\mathrm{SiO}_{2}$ normalized $\mathrm{FY}$ intensity value is between those of the $\mathrm{Ag}-\mathrm{SiO}_{2}-\mathrm{NH}_{2}$ and $\mathrm{Ag}$ PVP samples (Fig. 4a). The area under the curve is directly related to the total quantity of the target element.

At 24 hours, $\mathrm{Ag}-\mathrm{SiO}_{2} \mathrm{FY}$ shows a "double-peak" profile with a strong peak at $0.27^{\circ}$ and a weaker one at $0.10^{\circ}$. Ag-PVP has a wide $\mathrm{FY}$ peak with high $\mathrm{FY}$ value from $0.20^{\circ}$ to $0.30^{\circ}$. $\mathrm{Ag}-\mathrm{SiO}_{2}-$ $\mathrm{NH}_{2}$ profile has a sharper peak at $0.23^{\circ}$ than Ag-PVP. After 24 hours, $\mathrm{Ag}-\mathrm{SiO}_{2}$ has the highest normalized $\mathrm{FY}$ intensity followed by Ag-PVP and $\mathrm{Ag}-\mathrm{SiO}_{2}-\mathrm{NH}_{2}$ (Fig. 4b). 
a) Ag-PVP

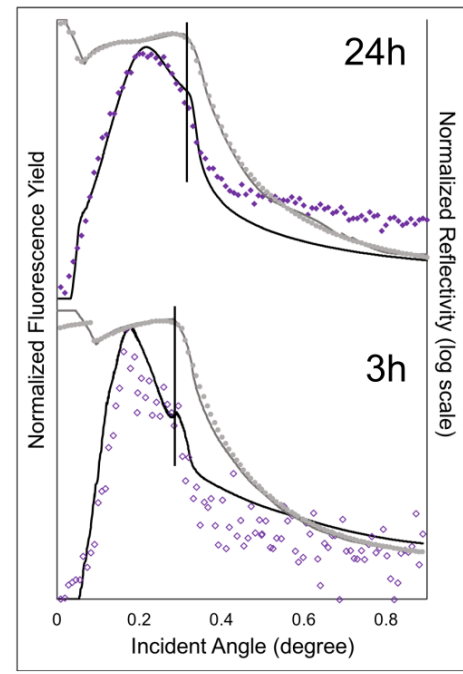

b) $\mathrm{Ag}-\mathrm{SiO}_{2}$

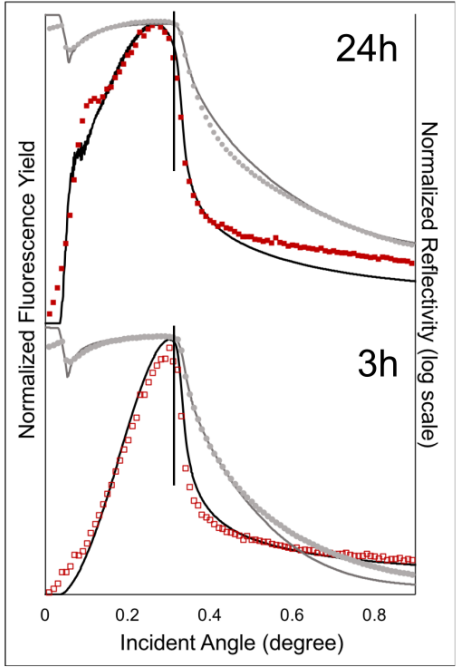

c) $\mathrm{Ag}-\mathrm{SiO}_{2}-\mathrm{NH}_{2}$

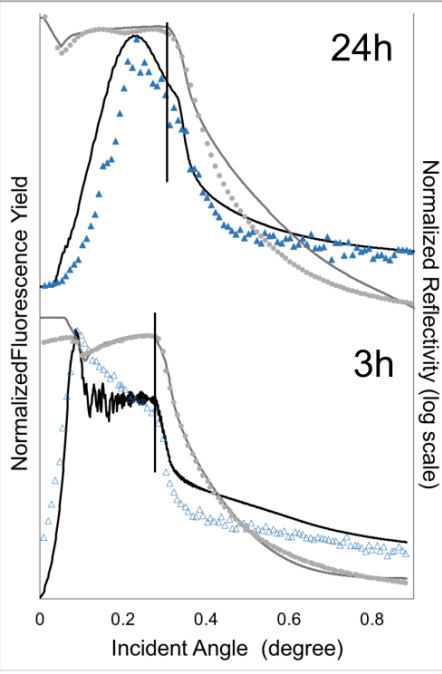

Figure 3: Observed and modelled LPXSW Ag La FY for Ag-PVP (a), Ag$\mathrm{SiO} 2$ (b) and $\mathrm{Ag}-\mathrm{SiO} 2-\mathrm{NH} 2$ (c) NPs in contact with $\mathrm{S}$. oneidensis MR-1 biofilm/ $\alpha-\mathrm{Al} 2 \mathrm{O} 3$ (1-102) substrate interface at $3 \mathrm{~h}$ and $24 \mathrm{~h}$. The black vertical lines mark the critical angle. Colourful symbol and grey circles correspond to observed data (fluorescence and reflectivity respectively) while continuous lines correspond to fits (black for fluorescence, grey for reflectivity). The dips in reflectivity at very low angle are related to slits and beam spill-off, and not a second critical angle.

\section{$\diamond$ \\ $\square \square:$ measured fluorescence $\quad$ — : modelled fluorescence $\quad \bullet$ : measured reflectivity $\quad$ : modelled reflectivity \\ $\Delta \Delta$}

The FY spectra collected at 24 hours exhibit higher fluorescence signal than the 3 hour profiles for Ag-PVP and Ag$\mathrm{SiO}_{2}$, while the opposite behaviour is observed for $\mathrm{Ag}-\mathrm{SiO}_{2}-\mathrm{NH}_{2}$ (Fig. 4a, b).

Ag uptake in biofilms after 24 hours, calculated from ICP-AES measurements, indicates that more Ag-PVP-NPs are concentrated in the biofilm than $\mathrm{Ag}-\mathrm{SiO}_{2}-\mathrm{NPs}$, at odds with the LP-XSW-FY observations (Fig. 4 b). One reason for this difference could be an incomplete dissolution of silica coated AgNPs in $2 \% \mathrm{HNO}_{3}$ before ICP-AES measurements, leading subsequently to a partial sorption of these NPs on the tubing walls.

The solution/biofilm/mineral interface does not present significant oscillations in $\mathrm{X}$-Ray reflectivity profiles indicating that biofilms are thick and rough. Average biofilm thicknesses (table S2) obtained by fitting reflectivity data are consistent with those measured in previous studies on similar systems ${ }^{18,}$ 19. The interface was modelled with three regions, 1) $100 \mathrm{~nm}$ below the substrate to the surface, 2) a surface region from 1 to $50 \mathrm{~nm}$ above the surface with a concentration of $\mathrm{Ag}$ and, 3) biofilm up to $6.5 \mu \mathrm{m}$ thick with concentration of Ag (Fig. S4). The gas/biofilm interface is also considered. The fluorescence yield fits obtained with this model are presented in Fig. 3 where black and grey lines represent respectively the fluorescence yield and the reflectivity. Partitioning of silver between the thick biofilm and the mineral surface, obtained by the fitting procedure is shown in Fig. 5.

Biofilm thicknesses determined from reflectivity models (LP-XSW-FY study) are only representative of the average biofilm thickness since biofilms are not homogeneous. They are several limitations to use reflectivity modelling to access to biofilm thickness. This technique is highly dependent of samples' roughness and thickness. To obtain the best reflectivity is better to work on thin homogeneous layer with low roughness. Biofilms are known to present high heterogeneity in thickness, density and roughness. Thus, modeling the reflectivity in sample with biofilm is quite complicated. Nevertheless, those parameters have been taken into account to model reflectivity. Biofilm thickness obtained by modeling reflectivity has to be interpret carefully but gives a good estimate of biofilms' thickness in those systems.

Uncertainties on the average biofilm as determined from the fit procedure are very small $(\mathrm{nm})$, but the real uncertainties are likely much larger given the inhomogeneity of the films. While it is difficult to determine the uncertainties on the biofilm thickness, we estimate them at $1 \mu \mathrm{m}$ using the method presented in annex 2 (SI). The modelled average thicknesses between 3 and 24 hours of exposure for Ag-PVP and $\mathrm{Ag}-\mathrm{SiO}_{2} \mathrm{NPs}$ are quite similar (table S2). For $\mathrm{Ag}-\mathrm{SiO}_{2}-\mathrm{NH}_{2}$ NPs the modelled biofilm thickness at 24 hours was 36\% smaller $(3.5 \pm 1 \mu \mathrm{m})$ than at 3 hours $(6.5 \pm 1 \mu \mathrm{m})$. This is consistent with the study of Fabrega et al.(2011) ${ }^{11}$ on AgNPs coated with citrate, which resulted in a loss of $41 \%$ in volume and $42 \%$ in biomass of biofilm exposed for 24 hours to AgNPs.

\section{Discussion}

\subsection{Effect of AgNPs on biofilm/crystal system}

At the beginning of the experiment, i.e. before exposure to AgNPs, the mineral surface is covered by the conditioning film and bacterial islands are dispersed on the surface (Fig. S2.1 a, b), as observed by SEM. After 24 hours of exposure to AgNPs, bacterial islands appeared smaller, and some bacteria appeared to be damaged with misshapen cells (Fig. S2.1 c, d, e). Li et al. (2010) ${ }^{43}$ observed similar damages on Escherichia coli planktonic cells exposed to Ag-NPs using SEM and TEM. This is also consistent with the study of Suresh et al.(2012) which reported a loss of cell density and an alteration of characteristic morphology when mouse macrophage cells were exposed to different AgNPs. Using phase contrast microscopy, they also showed that cells were shrunken, and that detached cells and cellular debris were found to be floating. In our study, the use of supercritical drying to prepare samples for SEM imaging might have led to biofilm compression and to the loss of the floating part of the damaged biofilm by gas flux during 
drying. Thus for our SEM observations, even if this procedure minimizes biologic structural degradation, it is important to note that supercritical drying can sometimes lead to artefacts and must be considered cautiously ${ }^{45}$.

\subsection{Factors controlling AgNPs interaction at solution/biofilm/mineral interface}

\subsubsection{Electrostatic interaction}

a) exposure time: $3 \mathrm{~h}$

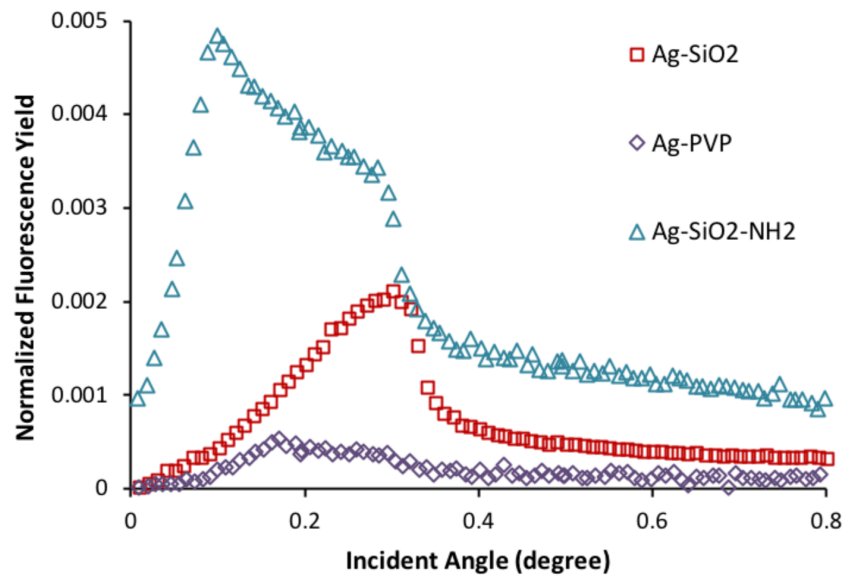

b) exposure time: $24 \mathrm{~h}$

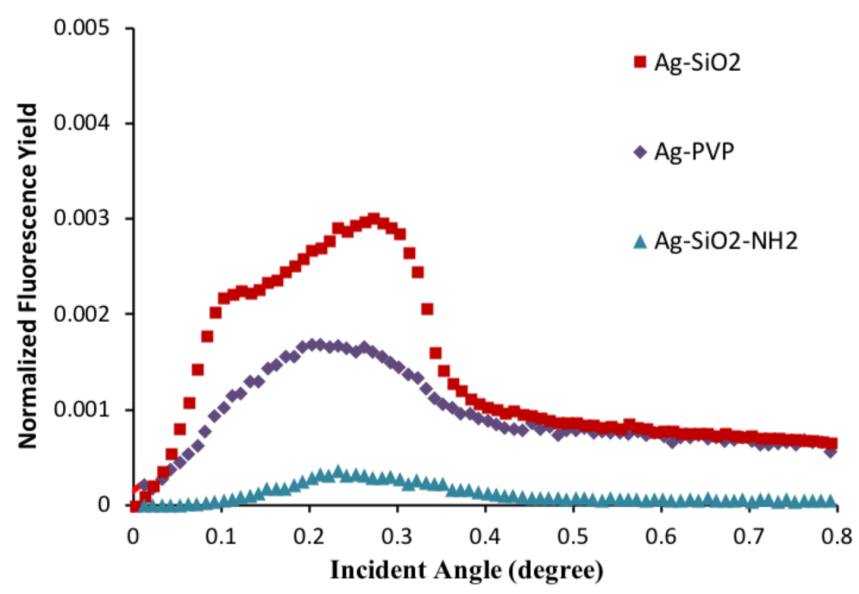

Figure 4: Observed LP-XSW Ag L $\alpha$ fluorescence yield (FY) profiles for different NPs' coating: Ag-SiO2-NH2 (triangles), $\mathrm{Ag}-\mathrm{SiO} 2$ (squares) and Ag-PVP (diamonds) exposed to solution/S. oneidensis MR-1 biofilm/ $\alpha$-Al2O3 (1-102) interface after (a) 3 hours (open symbols) and (b) 24 hours (closed symbols).

The increase in overall Ag FY intensity with time for Ag-PVP and $\mathrm{Ag}-\mathrm{SiO}_{2}$ is directly representative of an increase in $\mathrm{Ag}$ concentration at the solution/biofilm/mineral interface (Fig. 4). This relative increase demonstrates an accumulation by the interface over time. The amounts of $\mathrm{Ag}$ taken up by the biofilms in our study are similar to the one obtained in other studies investigating AgNPs toxic effects on biofilms ${ }^{11,28}$ for similar initial concentration (e.g: $0.53 \pm 0.05 \mu$ g uptake in our study for an initial quantity of $31.22 \pm 0.01 \mu \mathrm{g}$ versus an uptake between $0.10 \pm 0.02$ and $1.8 \pm 0.3$ for an initial quantity of $\left.22.8 \mu \mathrm{g}^{28}\right)$.

Since the biofilm in our study was oriented face down during AgNPs exposure, this increase in silver concentration at the interface cannot be the result of nanoparticle sedimentation, but is better explained by an affinity of NPs for the interface. Ag-PVP and $\mathrm{Ag}-\mathrm{SiO}_{2} \mathrm{NPs}$ are negatively charged, and they will be attracted by the amino groups present within the biofilm thickness and by the positives sites of the mineral surface. The isoelectric point (IEP) of $\alpha-\mathrm{Al}_{2} \mathrm{O}_{3}$ is usually reported in the $\mathrm{pH}$ range of 8 to 10 (compilation done by Wang et al.(2016) ${ }^{46}$ ), suggesting a positive charge for our mineral substrate at $\mathrm{pH} 7$. However, some studies on oriented single crystals ${ }^{46-48}$ have determined a lower isoelectric point value, in the $\mathrm{pH}$ range of 5.1 to 5.85 . For $\alpha-\mathrm{Al}_{2} \mathrm{O}_{3}$ (1-102), the surface charge difference between polycrystalline powders and oriented single crystals is potentially explained by the presence of highly reactive defect sites in polycrystalline material ${ }^{46}$. As a result, the single crystal IEP is highly sensitive to the surface morphology and presence of defects ${ }^{46}$, with for instance simulations on $\alpha-\mathrm{Al}_{2} \mathrm{O}_{3}$ (0001) showing that even very low concentrations of defects shift the IEP to substantially higher values. Also, the $\mathrm{pH}_{\text {IEP }}$ has been shown to be dependent on surface aging with a shift from 4 to 9 between fresh and aged $\alpha-\mathrm{Fe}_{2} \mathrm{O}_{3}$ (0001) surfaces ${ }^{49}$. In our study, the IEP value of $\alpha$ $\mathrm{Al}_{2} \mathrm{O}_{3}$ (1-102) covered by biofilms remains uncertain since the surface is exposed to bacteria cells able to alter the mineral surface, as shown for microbial-induced rock weathering ${ }^{50}$, potentially creating defects on the mineral surface. Thus, the surface charge value of $\alpha-\mathrm{Al}_{2} \mathrm{O}_{3}(1-102)$ at $\mathrm{pH} 7$ in our study can be considered as ranging from slightly positive to slightly negative. In any case, considering the highly negative charge of S. oneidensis MR-1 cells, with an IEP measured around $4.0^{39}$, the $\alpha-\mathrm{Al}_{2} \mathrm{O}_{3}(1-102)$ is much less negative and would constitute the "less negatively charged" part of the solution/biofilm/mineral interface.

The control of surface charge on AgNPs sorption was reported by Khan et al. $(2011)^{51}$ who showed that the interaction of AgNPs with bacterial extracellular proteins was dependent of the surface charge of AgNPs and proteins. Indeed, the sorption of AgNPs on extracellular proteins decreased by $90 \%$ when the $\mathrm{pH}$ was above 8 (i.e. the $\mathrm{pH}$ of point of zero charge of AgNPs). An opposite behaviour is observed for $\mathrm{Ag}-\mathrm{SiO}_{2}-\mathrm{NH}_{2} \mathrm{NPs}$ (Fig. 4 a vs. b) with a decrease in FY intensity between $3 \mathrm{~h}$ and $24 \mathrm{~h}$. Moreover, $\mathrm{Ag}-\mathrm{SiO}_{2}-\mathrm{NH}_{2} \mathrm{NPs}$ are the most concentrated AgNPs after 3 hours of exposure (Fig. 4a), which means that at 3 hours this type of AgNPs has the best affinity for the biofilm. Preferential interaction between positively charged NPs and negatively charged biofilm have already been observed ${ }^{44,52,53}$. In our study, at 3 hours there is a strong affinity between the $\mathrm{Ag}-\mathrm{SiO}_{2}-\mathrm{NH}_{2} \mathrm{NPs}$ and the biofilm. The strongest interaction between the biofilm and the $\mathrm{Ag}-\mathrm{SiO}_{2}-\mathrm{NH}_{2} \mathrm{NPs}$, due to electrostatics, favours the presence of AgNPs within the biofilm thickness. Their presence can lead to a toxic effect on bacteria and thus, induces a loss of bacteria between 3 and 24 hours. Actually, $\mathrm{Ag}-\mathrm{SiO}_{2}-\mathrm{NH}_{2} \mathrm{NPs}$ toxicity to the biofilm seems to be more significant than for the two others. The biofilm thickness after 24 hours of exposure is almost half the thickness of the one at 3 hours $(3.5 \pm 1 \mu \mathrm{m}$ vs $6.5 \pm 1 \mu \mathrm{m})$. As the biofilm is smaller at 24 hours, it is not able to trap more AgNPs which corresponds well to the decrease in fluorescence intensity from 3 hours to 24 hours. The higher toxicity of Ag$\mathrm{SiO}_{2}-\mathrm{NH}_{2} \mathrm{NPs}$ could also explain the difference of behaviour with the two others AgNPs. 


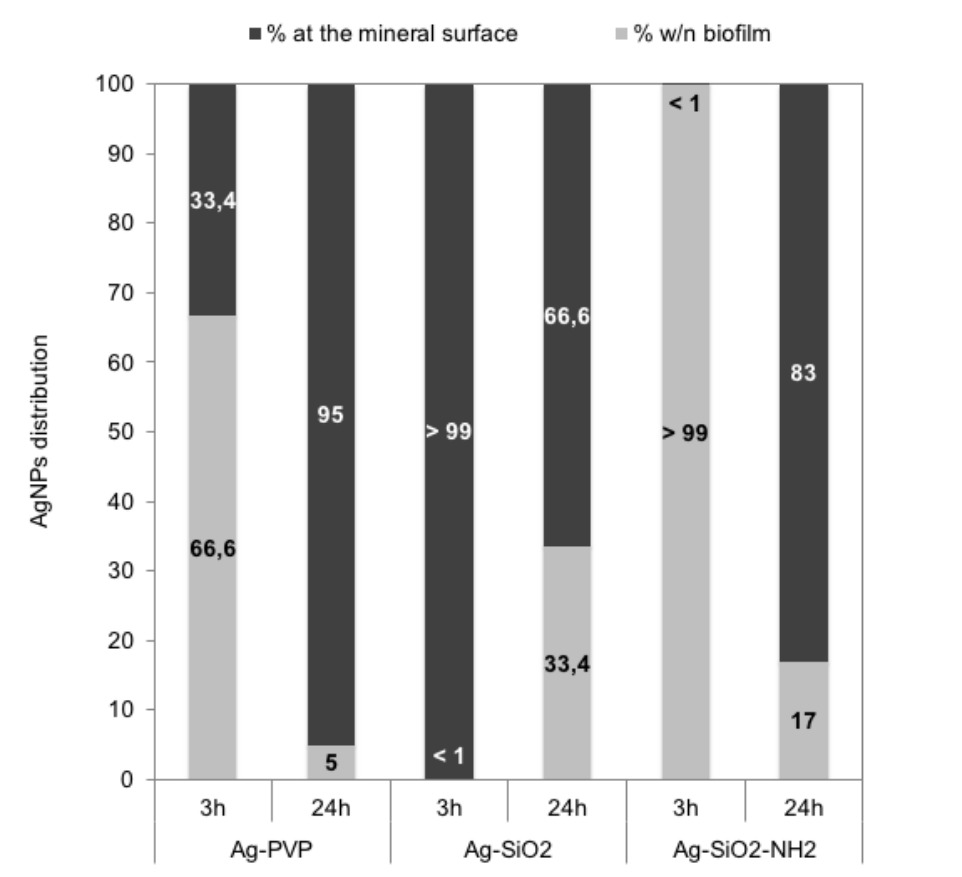

igure 5: Percentage of AgNPs present at the mineral surface and within the biofilm matrix ibtained by modelling LP-XSW-FY data.

For a given exposure time ( 3 or 24 hours), $\mathrm{Ag}-\mathrm{SiO}_{2} \mathrm{NPs}$ are more concentrated than Ag-PVP NPs (Fig. 4 a, b) in the biofilm, meaning that independent of their negative surface charge and similar zeta potential (table S1), the two AgNPs interact differently with the bio-interface. Moreover, in our SEM images Ag-PVP NPs are well-dispersed (Fig. S2.2 C) whereas Ag$\mathrm{SiO}_{2} \mathrm{NPs}$ are aggregated (Fig. S2.2 a) like $\mathrm{Ag}-\mathrm{SiO}_{2}-\mathrm{NH}_{2} \mathrm{NPs}$ which are positively charged (Fig. S2.2 b). The study of Golmohamadi et al., $2013^{54}$ on diffusion of differently charged $\mathrm{Au}$ and $\mathrm{TiO}_{2}$ NPs within Pseudomonas fluorescens biofilms of 17 hours shows similar trends which have the same diffusion properties highlighting the importance of size and local accumulation effect on NPs diffusion. In our study, Ag-PVP NPs are sterically stabilized while $\mathrm{Ag}-\mathrm{SiO}_{2}$ and $\mathrm{Ag}-\mathrm{SiO}_{2}-\mathrm{NH}_{2} \mathrm{NPs}$ are electrostatically stabilized. The difference of fate between $\mathrm{Ag}$ PVP and $\mathrm{Ag}-\mathrm{SiO}_{2} \mathrm{NPs}$ at the solution/biofilm/mineral interface could therefore be partly explained by the type of capping agent used to stabilize the AgNPs in solution, highlighting the importance of coating type.

\subsection{Partitioning between biofilm and mineral surface}

$$
\text { 4.3.1. } \mathrm{Ag}-\mathrm{SiO}_{2}
$$

At 3 hours of exposure, the model fit indicates that more than 99\% of $\mathrm{Ag}-\mathrm{SiO}_{2} \mathrm{NPs}$ are present at the mineral surface (Fig. 5). Thus, $\mathrm{Ag}-\mathrm{SiO}_{2} \mathrm{NPs}$ interact preferentially and quickly with the mineral surface. In a previous study ${ }^{18}$, biofilms do not seem to inhibit reactivity of the metal-oxide surface. The lack of interactions between $\mathrm{Ag}-\mathrm{SiO}_{2} \mathrm{NPs}$ and the biofilm could be caused by electrostatic repulsions between the biofilm and Ag$\mathrm{SiO}_{2}$ NPs which are both negatively charged. Indeed, NPs' surface charge is known to affect their interactions with biofilms ${ }^{44,52}$. In addition to this electrostatic control, this lack of interaction could also be influenced to a lesser extent by the size of Ag-NPs $(\sim 90 \mathrm{~nm})$ which are likely too large to be transported through the smallest biofilm channels, thus reducing the probability for $\mathrm{Ag}-\mathrm{SiO}_{2} \mathrm{NPs}$ interactions with the biofilm positively charged amino groups. It is known that micrometer size channels $(0.4 \text { to } 1 \mu \mathrm{m})^{55}$ are present within biofilm matrices, however it is quite difficult to assess the sizes of the smallest channels. Peulen and Wilkinson $(2011)^{27}$ estimate that the effective smallest pore size in a biofilm of Pseudomonas fluorescens ranges from below $10 \mathrm{~nm}$ up to 50 $\mathrm{nm}$. If channels in this size range are present within $S$. oneidensis biofilms, they might allow the transport of Ag-PVP $\mathrm{NPs}$ whereas $\mathrm{Ag}-\mathrm{SiO}_{2} \mathrm{NPs}$ are unlikely to penetrate the densest parts of the bacterial "islands", although they could access the mineral surface through the main water channels connecting the bottom of the biofilm to the bulk solution ${ }^{20}$. Finally, the mineral and $\mathrm{Ag}-\mathrm{SiO}_{2} \mathrm{NPs}$ both have hydrophilic surfaces which can favor interactions between them. NPs hydrophobic interactions have yet to be well-constrained. Nevertheless, some studies highlight their importance on NPs interactions with organic compounds 56,57 even if little is known about the mechanisms of interaction.

When the time of exposure increases to $24 \mathrm{~h}, \mathrm{Ag}-\mathrm{SiO}_{2} \mathrm{NPs}$ are still preferentially located at the mineral surface $(66.6 \%$, Fig. 5). However, a second peak at $0.1^{\circ}$ indicates that $\mathrm{Ag}-\mathrm{SiO}_{2}$ NPs start to interact with the biofilm (33.4\%, Fig. 5). The delayed interactions between $\mathrm{Ag}-\mathrm{SiO}_{2} \mathrm{NPs}$ and the biofilm suggests that the mineral surface has a higher affinity for the NPs than the biofilm, and that it approaches saturation before $\mathrm{Ag}-\mathrm{SiO}_{2} \mathrm{NPs}$ start to react with the amino groups of the biofilm (present at the surface of the bacteria and EPS) that are reported to form strong complexes with AgNPs and $\mathrm{SiO}_{2} \mathrm{NPs}^{58,}$ 59. Alternatively, as the mineral surface is covered by the negatively charged $\mathrm{Ag}-\mathrm{SiO}_{2} \mathrm{NPs}$ it might become less favorable for additional $\mathrm{Ag}-\mathrm{SiO}_{2}$ NPs to approach, causing them to remain in the biofilm or the solution.

\subsection{2. $\mathrm{Ag}-\mathrm{SiO}_{2}-\mathrm{NH}_{2}$}

At 3 hours, $\mathrm{Ag}-\mathrm{SiO}_{2}-\mathrm{NH}_{2} \mathrm{NPs}$ are located in the biofilm with more than $99 \%$ of $\mathrm{Ag}$ present in its thickness (model fit, Fig. 5). At short exposure times, at $\mathrm{pH} 7.0$, the $\mathrm{Ag}-\mathrm{SiO}_{2}-\mathrm{NH}_{2} \mathrm{NPs}$ probably react mostly with negatively charged carboxyl and phosphoric functional groups at the surface of the $S$. oneidensis cells by electrostatic bonding ${ }^{39}$. These fast interactions and the limited number of available sites can lead to the saturation of biofilm surface sites, which can in turn favour later interactions between the AgNPs and the mineral surface (24 hours profile). The profile at 24 hours is noisier, with a broad peak that spans the interface. $83 \%$ of $\mathrm{Ag}$ are located at the mineral surface while only $17 \%$ are present within the biofilm (Fig. 5). At 24 hours, the mineral surface does not exert strong electrostatic repulsion towards the positively charged AgNPs. Moreover, the mineral surface is fully covered by the conditioning film, meaning that carboxyl and phosphoric groups are also located close to the mineral surface, and could partly explain the occurrence of $\mathrm{Ag}-\mathrm{SiO}_{2-}$ $\mathrm{NH}_{2}$ NPs "linked" to the mineral surface at 24h. A similar solution/biofilm/mineral interface exposed to the metallic cation $\mathrm{Pb}^{2+}$, using biofilms of Burkholderia cepacia or $\mathrm{S}$. oneidensis with $\mathrm{Al}_{2} \mathrm{O}_{3}$ (0001 or 1-101) and $\mathrm{Fe}_{2} \mathrm{O}_{3}$ (0001) 
surfaces, showed that the cation $\mathrm{Pb}^{2+}$ was able to interact primarily with the mineral surface at low $\mathrm{Pb}$ concentration (100 nM) and for a long interaction time (24 hours) at a higher concentration $(10 \mu \mathrm{M})^{16,18}$.

\subsubsection{Ag-PVP}

Based on electrostatic considerations, a preferential accumulation at the mineral surface is expected for Ag-PVP NPs. At 3 hours, however, $66.6 \%$ of $\mathrm{Ag}$ are present within the biofilm thickness while only $33.4 \%$ are located at the mineral surface (Fig. 5). This observation indicates a higher affinity of $\mathrm{Ag}$-PVP NPs for the biofilm than $\mathrm{Ag}-\mathrm{SiO}_{2} \mathrm{NPs}$. The observed larger FY peak for 24 hours of exposure reveals an evolution in the interactions of Ag-PVP NPs at the solution/biofilm/mineral interface. After 24 hours, $95 \%$ are located at the mineral surface and only $5 \%$ are within the biofilm. In contrast, after 3 hours, $\mathrm{Ag}-\mathrm{SiO}_{2} \mathrm{NPs}$ go through the biofilm to the mineral surface. The difference in behavior between the two negatively charged AgNPs might be the result of various processes: the smaller size of Ag-PVP compared to $\mathrm{Ag}-\mathrm{SiO}_{2}(60$ $\mathrm{nm}$ vs $90 \mathrm{~nm}$ ) might induce a longer retention in the biofilm space because Ag-PVP is able to circulate in smaller pores and conduits and, therefore interact with higher concentrations of cells and EPS ${ }^{20,24}$. This will likely favor NPs interaction with areas of higher functional group density, because of the smaller channel cross section, thus providing more access to amino groups present at the cell surfaces ${ }^{39}$. In addition, a study of antibiotic and biofilm interactions shows that EPS can limit antibiotic diffusion through the biofilm thickness, and act as physical barrier ${ }^{22}$. Peulen and Wilkinson $(2011)^{27}$ conducted a study on AgNPs diffusion within a biofilms with various densities, depending on EPS concentrations modified by varying iron concentration, and showed that the presence of EPS decreases the diffusion rate. Furthermore, Kroll et al. $(2014)^{25}$ showed that despite the negative charge of carbonate-coated AgNPs and EPS from five different bacterial species, accumulation still occurs. In addition, Joshi et al.(2012) $)^{60}$ observed that interaction between EPS and Ag-PVP NPs prevents internalization of AgNPs. Thus, Ag-PVP NPs interactions with EPS is favored. Li et al. $(2016)^{26}$ have also demonstrated the decrease in $\mathrm{Ag}$ concentration in supernatants when EPS are present in solution indicating the formation of AgNPs-EPS complexes. Finally, Ag-PVP NPs are considered relatively hydrophobic ${ }^{56}$, and some portions of biofilms can be relatively hydrophobic, depending on the bacterial strain, lipid production, and localization within the biofilm thickness. Song et al. (2011) ${ }^{56}$ showed that two hydrophobic surfaces (Ag-PVP and modified OTS-coated glass) have the strongest interactions due to a local displacement of water molecules. Such reactions within biofilm thickness can have an important impact on the longer-term retention of $\mathrm{Ag}$ PVP.

\section{Conclusion}

The solution/biofilm/mineral system acts as a sink for AgNPs as previously observed for free-metal ions 16, 19 . Our study enables identification of the major parameters that control AgNPs interactions, reactivity and transport through the solution/biofilm/mineral interface. At first, electrostatic interactions are likely to control their global interactions with the interface. $\mathrm{LP}-\mathrm{XSW}-\mathrm{FY}$ data on $\mathrm{Ag}-\mathrm{SiO}_{2}-\mathrm{NH}_{2} \mathrm{NPS}$ show strong interactions between the positively charged NPs which preferentially accumulates in the negatively charged biofilm. However, the comparative study of both negatively charged AgNPs $\left(\mathrm{SiO}_{2}\right.$ and PVP) indicates other factors affect AgNPs behaviour at the solution $/$ biofilm $/$ mineral interface. For example, the size of the NPs as well as (in)organic and hydrophobic properties of the coating substantially impact the transport of AgNPs within the biofilm thickness by modifying their reactivity. These parameters were previously identified as important for controlling stability of NPs in solution ${ }^{32,33}$, and we have shown they are also important in controlling NPs distribution in biofilms. Previous studies have shown that aggregation of NPs tended to increase their stability and so decrease their bioavailability ${ }^{26,61}$. Thus, the agglomeration state of NPs could also strongly impact their transport through the biofilm thickness and mitigate their environmental impact. Using LP-XSW-FY modelling we obtain a better understanding of AgNPs fate at the solution/biofilm/mineral interface for the first time, since we are able to quantify their distribution. The distribution of AgNPs between the two compartments shows that biofilms do not block access to mineral surface sites.

This is the first study using LP-XSW-FY to study NPs interaction with biofilms, quantify those interactions and, more generally, investigate AgNPs fate in contact with a complex solution/biofilm/mineral interface. It allows exploration of such parameters as hydrophobicity, coating type and size on AgNPs transport within the biofilm thickness. Specifically, little is known about the role of hydrophobicity on interactions between biofilms and NPs. A recent study by Mitzel et al. $(2016)^{62}$ showed that biofilm hydrophobicity partly controls NPs transport in simplified soil columns. However, more studies are needed. Our present study provides new insights about how biofilms may impact AgNPs, and more generally NPs reactivity and transport in the environment.

\section{Conflicts of interest}

"There are no conflicts to declare".

\section{Acknowledgements}

This work was supported by the ANR QUADOS project, grant ANR14-CE01-0013-01 of the French Agence Nationale de la Recherche and project EC2CO-PRONTO financed by the Centre National de Recherche Scientifique (CNRS).

Portions of this work were performed at GeoSoilEnviroCARS (The University of Chicago, Sector 13), Advanced Photon Source, Argonne National Laboratory. GeoSoilEnviroCARS is supported by the National Science Foundation - Earth Sciences (EAR - 1634415) and Department of Energy- GeoSciences (DE-FG02-94ER14466). This research used resources of the Advanced Photon Source, a U.S. Department of Energy (DOE) Office of Science User Facility operated for the DOE Office of Science by Argonne National Laboratory under Contract No. DE-AC02-06CH11357.

The authors acknowledge Jessica Brest, at the Environmental Chemistry Platform (IMPMC), and Fériel Skouri-Planet, at the Biology Platform (IMPMC), for their help during experiments. 
SEM imagery and ICP-AES measurements were supported by IPGP multidisciplinary program PARI and by Region île-de-France SESAME Grant no. 12015908.

\section{Notes and references}

1. A. A. Keller, S. McFerran, A. Lazareva and S. Suh, Global life cycle releases of engineered nanomaterials, Journal of Nanoparticle Research, 2013, 15.

2. F. Piccinno, F. Gottschalk, S. Seeger and B. Nowack, Industrial production quantities and uses of ten engineered nanomaterials in Europe and the world, Journal of Nanoparticle Research, 2012, 14.

3. A. Massarsky, V. L. Trudeau and T. W. Moon, Predicting the environmental impact of nanosilver, Environ Toxicol Pharmacol, 2014, 38, 861-873.

4. C. Levard, E. M. Hotze, G. V. Lowry and G. E. Brown, Environmental Transformations of Silver Nanoparticles: Impact on Stability and Toxicity, Environmental Science \& Technology, 2012, 46, 6900-6914.

5. B. Wiley, Y. Sun, B. Mayers and Y. Xia, Shape-controlled synthesis of metal nanostructures: the case of silver, Chemistry, 2005, 11, 454-463.

6. T. Phenrat, N. Saleh, K. Sirk, H.-J. Kim, R. D. Tilton and G. V. Lowry, Stabilization of aqueous nanoscale zerovalent iron dispersions by anionic polyelectrolytes: adsorbed anionic polyelectrolyte layer properties and their effect on aggregation and sedimentation, Journal of Nanoparticle Research, 2007, 10, 795-814.

7. E. M. Hotze, T. Phenrat and G. V. Lowry, Nanoparticle Aggregation: Challenges to Understanding Transport and Reactivity in the Environment, Journal of Environment Quality, 2010, 39, 1909.

8. J. W. Card, D. C. Zeldin, J. C. Bonner and E. R. Nestmann, Pulmonary applications and toxicity of engineered nanoparticles, Am J Physiol Lung Cell Mol Physiol, 2008, 295, L400-411.

9. X. Ma, J. Geisler-Lee, Y. Deng and A. Kolmakov, Interactions between engineered nanoparticles (ENPs) and plants: phytotoxicity, uptake and accumulation, $\mathrm{Sci}$ Total Environ, 2010, 408, 3053-3061.

10. O. Choi, C. P. Yu, G. Esteban Fernandez and Z. Hu, Interactions of nanosilver with Escherichia coli cells in planktonic and biofilm cultures, Water Res, 2010, 44, 6095-6103.

11. J. Fabrega, R. Zhang, J. C. Renshaw, W. T. Liu and J. R. Lead, Impact of silver nanoparticles on natural marine biofilm bacteria, Chemosphere, 2011, 85, 961-966.

12. M. Marianne, K. Jurkschat and T. Backhaus, Toxicity of differently sized and coated silver nanoparticles to the bacterium Pseudomonas putida: risks for the aquatic environment?, Peer J Pre Prints, 2014, DOI: 10.7287/peerj.preprints.26v2.

13. F. Gottschalk, T. Sonderer, R. W. Scholz and B. Nowack, Modeled Environmental Concentrations of Engineered Nanomaterials (TiO2, ZnO, Ag, CNT, Fullerenes) for Different Regions, Environmental Science \& Technology, 2009, 43, 9216-9222.

14. T. Y. Sun, N. A. Bornhöft, K. Hungerbühler and B. Nowack, Dynamic Probabilistic Modeling of Environmental Emissions of Engineered Nanomaterials, Environmental Science \& Technology, 2016, 50, 4701-4711.
15. G. E. Brown, V. E. Henrich, W. H. Casey, D. L. Clark, C. Eggleston, A. Felmy, D. W. Goodman, M. Grätzel, G. Maciel, M. I. McCarthy, K. H. Nealson, D. A. Sverjensky, M. F. Toney and J. M. Zachara, Metal Oxide Surfaces and Their Interactions with Aqueous Solutions and Microbial Organisms, Chemical Reviews, 1999, 99, 77-174.

16. A. S. Templeton, T. P. Trainor, S. J. Traina, A. M. Spormann and $\mathrm{G}$. E. Brown, $\mathrm{Pb}(\mathrm{II})$ distributions at biofilm-metal oxide interfaces, Proceedings of the National Academy of Sciences, 2001, 98, 11897-11902.

17. A. S. Templeton, T. P. Trainor, A. M. Spormann, M. Newville, S. R. Sutton, A. Dohnalkova, Y. Gorby and G. E. Brown, Sorption versus Biomineralization of $\mathrm{Pb}(\mathrm{II})$ within Burkholderia cepacia Biofilms, Environmental Science \& Technology, 2003, 37, 300-307.

18. Y. Wang, A. Gélabert, F. M. Michel, Y. Choi, J. Gescher, G. Ona-Nguema, P. J. Eng, J. R. Bargar, F. Farges, A. M. Spormann and G. E. Brown, Effect of biofilm coatings at metal-oxide/water interfaces $\mathrm{I}: \mathrm{Pb}$ (II) and $\mathrm{Zn}(\mathrm{II})$ partitioning and speciation at Shewanella oneidensis/metal-oxide/water interfaces, Geochimica et Cosmochimica Acta, 2016, 188, 368-392.

19. Y. Wang, A. Gélabert, F. M. Michel, Y. Choi, P. J. Eng, A. M. Spormann and G. E. Brown, Effect of biofilm coatings at metal-oxide/water interfaces II: Competitive sorption between $\mathrm{Pb}(\mathrm{II})$ and $\mathrm{Zn}(\mathrm{II})$ at Shewanella oneidensis/metaloxide/water interfaces, Geochimica et Cosmochimica Acta, 2016, 188, 393-406.

20. J. W. Costerton, Z. Lewandowski, D. E. Caldwell, D. R. Korber and H. M. Lappin-Scott, Microbial Biofilms, Annual Review of Microbiology, 1995, 49, 711-745.

21. R. Bos, H. C. van der Mei and H. J. Busscher, Physicochemistry of initial microbial adhesive interactions - its mechanisms and methods for study, FEMS Microbiology Reviews, 1999, 23, 179-230.

22. P. S. Stewart and W. J. Costerton, Antibiotic resistance of bacteria in biofilms, The Lancet, 2001, 358, 135-138.

23. H. C. Flemming and J. Wingender, The biofilm matrix, Nat Rev Microbiol, 2010, 8, 623-633.

24. M. E. Davey and G. A. O'Toole, Microbial Biofilms: from Ecology to Molecular Genetics, Microbiology and Molecular Biology Reviews, 2000, 64, 847-867.

25. A. Kroll, R. Behra, R. Kaegi and L. Sigg, Extracellular polymeric substances (EPS) of freshwater biofilms stabilize and modify $\mathrm{CeO} 2$ and $\mathrm{Ag}$ nanoparticles, PLOS One, 2014, 9, e110709.

26. C.-C. Li, Y.-J. Wang, F. Dang and D.-M. Zhou, Mechanistic understanding of reduced AgNP phytotoxicity induced by extracellular polymeric substances, Journal of Hazardous Materials, 2016, 308, 21-28.

27. T.-O. Peulen and K. J. Wilkinson, Diffusion of Nanoparticles in a Biofilm, Environmental Science \& Technology, 2011, 45, 3367-3373.

28. J. Fabrega, J. C. Renshaw and J. R. Lead, Interactions of Silver Nanoparticles with Pseudomonas putida Biofilms, Environmental Science \& Technology, 2009, 43, 90049009.

29. M. Delay, T. Dolt, A. Woellhaf, R. Sembritzki and F. H. Frimmel, Interactions and stability of silver nanoparticles in the aqueous phase: Influence of natural organic matter (NOM) and ionic strength, J Chromatogr A, 2011, 1218, 4206-4212. 
30. S. Klitzke, G. Metreveli, A. Peters, G. E. Schaumann and F. Lang, The fate of silver nanoparticles in soil solution Sorption of solutes and aggregation, Science of The Total Environment, 2015, 535, 54-60.

31. A. E. Pradas del Real, H. Castillo-Michel, R. Kaegi, B. Sinnet, V. Magnin, N. Findling, J. Villanova, M. Carrière, C. Santaella, A. Fernández-Martínez, C. Levard and G. Sarret, Fate of Ag-NPs in Sewage Sludge after Application on Agricultural Soils, Environmental Science \& Technology, 2016, 50, 1759-1768.

32. L. Kvítek, A. Panáček, J. Soukupová, M. Kolář, R. Večeřová, R. Prucek, M. Holecová and R. Zbořil, Effect of Surfactants and Polymers on Stability and Antibacterial Activity of Silver Nanoparticles (NPs), The Journal of Physical Chemistry C, 2008, 112, 5825-5834.

33. N. S. Wigginton, A. d. Titta, F. Piccapietra, J. Dobias, V. J. Nesatyy, M. J. F. Suter and R. Bernier-Latmani, Binding of Silver Nanoparticles to Bacterial Proteins Depends on Surface Modifications and Inhibits Enzymatic Activity, Environmental Science \& Technology, 2010, 44, 21632168.

34. C. Levard, F. M. Michel, Y. Wang, Y. Choi, P. Eng and G. E. Brown, Jr., Probing Ag nanoparticle surface oxidation in contact with (in)organics: an X-ray scattering and fluorescence yield approach, J Synchrotron Radiat, 2011, 18, 871-878.

35. C. Levard, B. C. Reinsch, F. M. Michel, C. Oumahi, G. V. Lowry and G. E. Brown, Sulfidation Processes of PVPCoated Silver Nanoparticles in Aqueous Solution: Impact on Dissolution Rate, Environmental Science \& Technology, 2011, 45, 5260-5266.

36. D. R. U. S. G. S. Lovely, Reston, VA.), Microbial reduction of iron, manganese, and other metals, 1995, v. 54.

37. R. G. Arnold, M. R. Hoffmann, T. J. Dichristina and F. W. Picardal, REGULATION OF DISSIMILATORY FE(III) REDUCTION ACTIVITY IN SHEWANELLA-PUTREFACIENS, Appl. Environ. Microbiol., 1990, 56, 2811-2817.

38. J. F. Heidelberg, I. T. Paulsen, K. E. Nelson, E. J. Gaidos, W. C. Nelson, T. D. Read, J. A. Eisen, R. Seshadri, N. Ward, B. Methe, R. A. Clayton, T. Meyer, A. Tsapin, J. Scott, M. Beanan, L. Brinkac, S. Daugherty, R. T. DeBoy, R. J. Dodson, A. S. Durkin, D. H. Haft, J. F. Kolonay, R. Madupu, J. D. Peterson, L. A. Umayam, O. White, A. M. Wolf, J. Vamathevan, J. Weidman, M. Impraim, K. Lee, K. Berry, C. Lee, J. Mueller, H. Khouri, J. Gill, T. R. Utterback, L. A. McDonald, T. V. Feldblyum, H. O. Smith, J. C. Venter, K. H. Nealson and C. M. Fraser, Genome sequence of the dissimilatory metal ion-reducing bacterium Shewanella oneidensis, Nat Biotechnol, 2002, 20, 1118-1123.

39. J. Ha, A. Gélabert, A. M. Spormann and G. E. Brown, Role of extracellular polymeric substances in metal ion complexation on Shewanella oneidensis: Batch uptake, thermodynamic modeling, ATR-FTIR, and EXAFS study, Geochimica et Cosmochimica Acta, 2010, 74, 1-15.

40. A. Templeton and E. Knowles, Microbial Transformations of Minerals and Metals: Recent Advances in Geomicrobiology Derived from Synchrotron-Based X-Ray Spectroscopy and X-Ray Microscopy, Annual Review of Earth and Planetary Sciences, 2009, 37, 367-391.

41. J. R. Lawrence, J. J. Dynes, D. R. Korber, G. D. W. Swerhone, G. G. Leppard and A. P. Hitchcock, Monitoring the fate of copper nanoparticles in river biofilms using scanning transmission X-ray microscopy (STXM), Chemical Geology, 2012, 329, 18-25.

42. J. R. Lawrence, G. D. Swerhone, J. J. Dynes, D. R. Korber and A. P. Hitchcock, Soft X-ray spectromicroscopy for speciation, quantitation and nano-eco-toxicology of nanomaterials, J Microsc, 2016, 261, 130-147.

43. W. R. Li, X. B. Xie, Q. S. Shi, H. Y. Zeng, Y. S. Ou-Yang and Y. B. Chen, Antibacterial activity and mechanism of silver nanoparticles on Escherichia coli, Appl Microbiol Biotechnol, 2010, 85, 1115-1122.

44. A. K. Suresh, D. A. Pelletier, W. Wang, J. L. Morrell-Falvey, B. $\mathrm{Gu}$ and M. J. Doktycz, Cytotoxicity induced by engineered silver nanocrystallites is dependent on surface coatings and cell types, Langmuir, 2012, 28, 2727-2735.

45. S. Schädler, C. Burkhardt and A. Kappler, Evaluation of Electron Microscopic Sample Preparation Methods and Imaging Techniques for Characterization of Cell-Mineral Aggregates, Geomicrobiology Journal, 2008, 25, 228-239.

46. Y. Wang, P. Persson, F. M. Michel and G. E. Brown, Comparison of isoelectric points of single-crystal and polycrystalline $\alpha$-Al2O3and $\alpha$-Fe2O3surfaces, American Mineralogist, 2016, 101, 2248-2259.

47. J. P. Fitts, X. Shang, G. W. Flynn, T. F. Heinz and K. B. Eisenthal, Electrostatic Surface Charge at Aqueous/ $\alpha$ Al2O3 Single-Crystal Interfaces as Probed by Optical Second-Harmonic Generation, The Journal of Physical Chemistry B, 2005, 109, 7981-7986.

48. G. V. Franks and L. Meagher, The isoelectric points of sapphire crystals and alpha-alumina powder, Colloids and Surfaces A: Physicochemical and Engineering Aspects, 2003, 214, 99-110.

49. J. Lutzenkirchen, F. Heberling, F. Supljika, T. Preocanin, N. Kallay, F. Johann, L. Weisser and P. J. Eng, Structurecharge relationship - the case of hematite (001), Faraday Discussions, 2015, 180, 55-79.

50. G. M. Gadd, Metals, minerals and microbes: geomicrobiology and bioremediation, Microbiology, 2010, 156, 609-643.

51. S. S. Khan, P. Srivatsan, N. Vaishnavi, A. Mukherjee and N. Chandrasekaran, Interaction of silver nanoparticles (SNPs) with bacterial extracellular proteins (ECPs) and its adsorption isotherms and kinetics, J Hazard Mater, 2011, 192, 299-306

52. A. M. E. Badawy, R. G. Silva, B. Morris, K. G. Scheckel, M. T. Suidan and T. M. Tolaymat, Surface Charge-Dependent Toxicity of Silver Nanoparticles, Environmental Science \& Technology, 2011, 45, 283-287.

53. N. B. Saleh, B. Chambers, N. Aich, J. Plazas-Tuttle, H. N. Phung-Ngoc and M. J. Kirisits, Mechanistic lessons learned from studies of planktonic bacteria with metallic nanomaterials: implications for interactions between nanomaterials and biofilm bacteria, Front Microbiol, 2015 6, 677.

54. M. Golmohamadi, R. J. Clark, J. G. C. Veinot and K. J. Wilkinson, The role of charge on the diffusion of solutes and nanoparticles (silicon nanocrystals, nTiO2, nAu) in a biofilm, Environmental Chemistry, 2013, 10, 34.

55. P. L. Bishop, Biofilm structire and kinetics, Water Science and Technology, 1997, 36, 287-294.

J. E. Song, T. Phenrat, S. Marinakos, Y. Xiao, J. Liu, M. R. Wiesner, R. D. Tilton and G. V. Lowry, Hydrophobic interactions increase attachment of gum Arabic- and PVP- 
coated Ag nanoparticles to hydrophobic surfaces, Environ Sci Technol, 2011, 45, 5988-5995.

57. J. V. Maya Girón, R. V. Vico, B. Maggio, E. Zelaya, A. Rubert, G. Benítez, P. Carro, R. C. Salvarezza and M. E. Vela, Role of the capping agent in the interaction of hydrophilic Ag nanoparticles with DMPC as a model biomembrane, Environ. Sci.: Nano, 2016, 3, 462-472.

58. L. Li, W. Gu, J. Liu, S. Yan and Z. P. Xu, Aminefunctionalized $\mathrm{SiO} 2$ nanodot-coated layered double hydroxide nanocomposites for enhanced gene delivery, Nano Research, 2014, 8, 682-694.

59. L. Biao, S. Tan, Y. Wang, X. Guo, Y. Fu, F. Xu, Y. Zu and Z. Liu, Synthesis, characterization and antibacterial study on the chitosan-functionalized $\mathrm{Ag}$ nanoparticles, Mater Sci Eng C Mater Biol Appl, 2017, 76, 73-80.

60. N. Joshi, B. T. Ngwenya and C. E. French, Enhanced resistance to nanoparticle toxicity is conferred by overproduction of extracellular polymeric substances, $J$ Hazard Mater, 2012, 241-242, 363-370.

61. T. Diedrich, A. Dybowska, J. Schott, E. Valsami-Jones and E. H. Oelkers, The dissolution rates of $\mathrm{SiO} 2$ nanoparticles as a function of particle size, Environ Sci Technol, 2012, 46, 4909-4915.

62. M. R. Mitzel, S. Sand, J. K. Whalen and N. Tufenkji, Hydrophobicity of biofilm coatings influences the transport dynamics of polystyrene nanoparticles in biofilm-coated sand, Water Res, 2016, 92, 113-120. 